\title{
GRANDES OBRAS - BARRAGENS
}

\begin{tabular}{|c|c|}
\hline Título & Barragens: da política oficial à resistência dos atingidos \\
\hline Autor/es & Editorialistas de Travessia \\
\hline Resumo & Editorial \\
\hline Ano/Edição & Ano II, no 6, jan-abril/1990. São Paulo \\
\hline Título & Carta de Goiânia \\
\hline Autor/es & $\begin{array}{l}\text { Participantes do } 1 \text { Encontro Nacional dos Atingidos por } \\
\text { Barragens }\end{array}$ \\
\hline Resumo & Carta \\
\hline Ano/Edição & Ano II, no 6, jan-abril/1990. São Paulo \\
\hline Título & Intervenções e armadilhas de grande porte \\
\hline Autor/es & Antônio Oswaldo Servá Filho \\
\hline Resumo & $\begin{array}{l}\text { Aborda-se os desdobramentos e consequências sociais, } \\
\text { ambientais, políticas e culturais dos grandes projetos, como } \\
\text { barragens hidrelétricas, sobre populações e ecossistemas } \\
\text { atingidos; as formas de organização popular para salvaguardar } \\
\text { seus territórios ou conseguir ressarcimento de parte dos } \\
\text { prejuízos materiais, morais, ambientais, culturais sofridos, } \\
\text { por um lado, e, por outro, o tratamento que os Estados, } \\
\text { inclusive o brasileiro, da às populações atingidas, quando não } \\
\text { as marginalizando, escamoteando as suas demandas como } \\
\text { irracionais, emotivas e atrasadas. }\end{array}$ \\
\hline Ano/Edição & Ano II, no 6, jan-abril/1990. São Paulo \\
\hline
\end{tabular}

\begin{tabular}{ll}
\hline Título & O planejamento do setor elétrico brasileiro \\
Autor/es & Emílio Lèbre La Rovere \\
Resumo & O debate sobre grandes projetos inevitavelmente coloca \\
& algumas perguntas cruciais, que têm de ser respondidas. Para \\
& que se constroemasgrandes barragens? Quem se beneficia com \\
a produção dessa eletricidade? É absolutamente indispensável & realizar essas obras para se ter a energia necessária ao \\
& funcionamento da nossa sociedade? Há alternativas para \\
& evitar os impactos negativos desses empreendimentos? Para \\
& se obter elementos de resposta a essas questões, é necessário \\
& conhecer como se faz a política energética no Brasil e quais são \\
& os principais problemas encontrados no planejamento do setor. \\
& Este trabalho pretende contribuir nesse sentido, esclarecendo
\end{tabular}




\begin{tabular}{|c|c|}
\hline Ano/Edição & $\begin{array}{l}\text { alguns pontos que precisam ser melhor analisados e discutidos } \\
\text { no debate atual sobre as grandes barragens no Brasil. } \\
\text { Ano II, no 6, jan-abril/1990. São Paulo }\end{array}$ \\
\hline Título & $\begin{array}{l}\text { Implantação de grandes hidrelétricas: estratégias do setor } \\
\text { elétrico, estratégias das populações atingidas }\end{array}$ \\
\hline Autor/es & Carlos B. Vainer; Frederico Guilherme B. de Araujo \\
\hline Resumo & $\begin{array}{l}\text { O artigo discute sobre processos políticos, sociais e econômicos } \\
\text { de implantação de grandes hidrelétricas e considera os seus } \\
\text { fortes impactos ambientais e sociais. Propõe reflexões sobre } \\
\text { em que condições deverá ocorrer a participação popular nas } \\
\text { tomadas de decisões sobre as necessidades energéticas a serem } \\
\text { atendidas, os custos sociais e ambientais a serem ressarcidos, } \\
\text { etc. A participação dos atingidos ficará confinada aos esforços } \\
\text { para mitigar os impactos negativos das obras ou ocorreá } \\
\text { no momento em que se opta por um padrão de produção } \\
\text { e distribuição de eletricidade, no qual, portanto, é possível } \\
\text { conceber modelos alternativos ao atualmente vigente? }\end{array}$ \\
\hline Ano/Edição & Ano II, no 6, jan-abril/1990. São Paulo \\
\hline Título & $\begin{array}{l}\text { As políticas de gestão da força de trabalho e as condições de } \\
\text { vida do trabalhador das obras barrageiras }\end{array}$ \\
\hline Autor/es & Ângela M. Tude de Souza \\
\hline Resumo & $\begin{array}{l}\text { Aborda-se as estratégias das empresas privadas e públicas } \\
\text { na formação da gestão da força de trabalho nos grandes } \\
\text { projetos. Observa-se que no início da obra, o maior aumento } \\
\text { populacional decorre diretamente do recrutamento de pessoal } \\
\text { com experiência para a preparação, a locação e a apropriação } \\
\text { do canteiro de obras. A população dita interna cresce mais } \\
\text { do que a externa, salvo casos em que a antecipação de ações } \\
\text { se desenvolva com base no alojamento das populações } \\
\text { trabalhadoras externamente a seu canteiro, forte presença } \\
\text { de firmas especializadas sub-contratadas para serviços de } \\
\text { sondagem e locação. }\end{array}$ \\
\hline Ano/Edição & Ano II, no 6, jan-abril/1990. São Paulo \\
\hline Título & $\begin{array}{l}\text { Alto Uruguai: migração forçada e a reatualização da } \\
\text { identidade camponesa }\end{array}$ \\
\hline $\begin{array}{l}\text { Autor/es } \\
\text { Resumo }\end{array}$ & $\begin{array}{l}\text { Ilse Scherer-Warren; Maria José Reis; Neuza Maria Bloemer } \\
\text { A partir da década de } 50 \text { instala-se no Brasil uma política de } \\
\text { produção de energia, com vista à independência do país neste }\end{array}$ \\
\hline
\end{tabular}


setor. Este sonho é alimentado, de modo especial desde a década de 70 , através da elaboração e execução de projetos e construção de hidrelétricas de grande porte. Sonhou-se, na verdade, que a energia hidrelétrica era "barata", "limpa" e "renovável". Exemplos brasileiros provenientes de projetos desta natureza, já executados ou em execução, permitem questionar uma a um estes pressupostos. Este é um dos focos desse artigo, além de apontar para os movimentos migratórios de camponeses e também de organização dos atingidos por barragens no bojo das grandes obras.

Ano/Edição Ano II, no 6, jan-abril/1990. São Paulo

\begin{tabular}{ll}
\hline Título & Malária, migrações e grandes projetos na Amazônia \\
Autor/es & $\begin{array}{l}\text { Alberto Najar } \\
\text { Resumo }\end{array}$ \\
$\begin{array}{l}\text { Este trabalho pretende mostrar que a relação entre o enorme } \\
\text { crescimento da malária no Brasil e particularmente na região }\end{array}$ \\
$\begin{array}{l}\text { Amazônica não é, como procuram insinuar alguns documentos } \\
\text { oficiais, uma consequência das condições climáticas. Estas } \\
\text { explicações procuram passar uma ideia desbravadora e pioneira } \\
\text { cuja contrapartida são os inevitáveis custos para a saúde. Tudo } \\
\text { acaba indo para a conta do progresso. Quando muito, admite- } \\
\text { se que "componentes socioeconômicos representem fatores } \\
\text { importantes na transmissão da malária" (Arcoverde, 1985) } \\
\text { prevalecendo a visão de que os determinantes da história } \\
\text { da endemia são fundamentalmente fatores biológicos e } \\
\text { ecológicos num sentido restrito. } \\
\text { Ano II, no 6, jan-abril/1990. São Paulo }\end{array}$ \\
\hline Ano/Edição
\end{tabular}

\begin{tabular}{|c|c|}
\hline Título & $\begin{array}{l}\text { Alternativas às hidrelétricas na região amazônica - o caso de } \\
\text { Ji-Paraná }\end{array}$ \\
\hline Autor/es & Luiz Bassegio \\
\hline Resumo & $\begin{array}{l}\text { Enquanto o governo brasileiro planeja construir algumas } \\
\text { dezenas de lagos artificiais na região amazônica para atender } \\
\text { a uma demanda sempre crescente de energia, diversas } \\
\text { entidades, como sindicatos, associações de defesa do meio } \\
\text { ambiente e Igrejas comprometidas com a causa popular } \\
\text { organizam uma luta de resistência a estes projetos. Entretanto, } \\
\text { não basta não aceitar as consequências nefastas destas obras, } \\
\text { é preciso apresentar alternativas concretas e viáveis a estes } \\
\text { projetos. É o que pretendemos fazer nesse artigo. }\end{array}$ \\
\hline Ano/Edição & Ano II, no 6, jan-abril/1990. São Paulo \\
\hline
\end{tabular}




\begin{tabular}{|c|c|}
\hline Título & $\begin{array}{l}\text { Lutas, vitórias e desafios: a resistência no Alto Uruguai } \\
\text { (Relato de experiência) }\end{array}$ \\
\hline Autor/es & Luiz Alencar Dalla Costa \\
\hline Resumo & Relato de experiência \\
\hline Ano/Edição & Ano II, no 6, jan-abril/1990. São Paulo \\
\hline \multirow{4}{*}{$\begin{array}{l}\text { Título } \\
\text { Autor/es } \\
\text { Resumo } \\
\text { Ano/Edição }\end{array}$} & Migrar e morar (Editorial) \\
\hline & Dirceu Cutti \\
\hline & Editorial \\
\hline & Ano V, no 14, set-dez/1992. São Paulo \\
\hline \multirow{3}{*}{$\begin{array}{l}\text { Título } \\
\text { Autor/es } \\
\text { Resumo }\end{array}$} & $\begin{array}{l}\text { Acampamento de grande projeto: uma forma de imobilização } \\
\text { da força de trabalho pela moradia }\end{array}$ \\
\hline & Gustavo Lins Ribeiro \\
\hline & $\begin{array}{l}\text { A partir da Revolução Industrial, grandes projetos, como } \\
\text { a construção de canais, ferrovias, cidades e hidrelétricas, } \\
\text { possuemumahistóriaintimamenterelacionadacoma expansão } \\
\text { do capitalismo. Seja por causa das poderosas articulações } \\
\text { de interesses públicos e privados por eles realizadas, seja } \\
\text { pela gigantesca mobilização de capital e trabalhadores que } \\
\text { provocam, ou ainda pelo estabelecimento de novos sistemas } \\
\text { regionais explicitamente vinculados à economia capitalista } \\
\text { como um todo. Na história dos grandes projetos, encontramos } \\
\text { uma transmissão de modelos de organização do processo } \\
\text { produtivo e de administração da força de trabalho. O principal } \\
\text { ator social portador deste modelo no tempo é o engenheiro e, } \\
\text { por extensão, sua expressão coletiva: a escola de engenharia } \\
\text { e a empreiteira. Os engenheiros, através da acumulação de } \\
\text { conhecimentos herdados via educação e experiência prática, } \\
\text { reproduzem soluções modelares ao início de cada obra. É } \\
\text { por esta razão que os grandes projetos podem ser pensados } \\
\text { como uma forma de produção que mantém características } \\
\text { estruturais semelhantes em diferentes contextos geográficos } \\
\text { e históricos (Ribeiro } 1985,1987 \text { ). }\end{array}$ \\
\hline & Ano V, no 14, set-dez/1992. São Paulo \\
\hline
\end{tabular}

